\title{
Pítica 1 de Píndaro
}

\author{
Ricardo Tieri de Brito*, Christian Werner ${ }^{* *}$
}

RESUMO: Apresenta-se uma tradução para o português da Pítica 1 de Píndaro, realizada com base no texto grego editado por Snell e Mahler (1980), acompanhada de uma pequena introdução e notas.

Palavras-chave: Sicília; epinício; Píndaro; tirania; Hierão de Siracusa.

ABSTRACT: A translation into Portuguese of Pindar's Pythian 1 is presented along with a little introduction and notes, based upon the Greek text edited by Snell and Mahler (1980).

Keywords: Sicily; epinikion; Pindar, tyranny; Hieron of Syracuse.

\section{Introdução}

A obra poética do tebano Píndaro, que nasceu por volta de 518 a.C. ${ }^{1}$ (RACE, 2012, p. 5), se espraia por cerca de 52 anos $^{2}$, entre os períodos chamados Arcaico e Clássico da história da Grécia antiga, época de profundas transformações e conflitos, tanto no âmbito da Grécia balcânica quanto do resto do território ocupado por grupos de origem grega na região do Mediterrâneo ${ }^{3}$. Parte do corpus pindárico sobreviveu até nossos dias apenas na forma de fragmentos e um único grupo de poemas, os epinícios, foi transmitido com relativa integridade desde a Antiguidade.

O epinício é uma espécie da poesia mélica coral destinada a celebrar a vitória atlética de homens oriundos de camadas aristocráticas da população grega no contexto dos Jogos Pan-helênicos ${ }^{4}$. Os festivais, de natureza cívica e religiosa, eram sediados em santuários de importância regional ou pan-helênica e capazes de reunir um público diverso, oriundo de diversas pólis pertencentes ao amplo território ocupado por gregos

\footnotetext{
* Cursa graduação em Letras com habilitação em Grego na Faculdade de Filosofia, Letras e Ciências Humanas da Universidade de São Paulo (FFLCH-USP). É graduado em Direito na Faculdade de Direito de Ribeirão Preto da Universidade de São Paulo (FDRP-USP).

${ }^{* *}$ Professor de Língua e Literatura Grega na Universidade de São Paulo desde 2002. Licenciado em Letras (Português e Grego) pela Universidade Federal do Rio Grande do Sul (1996), é mestre (1999) e doutor (2004) em Letras Clássicas pela Universidade de São Paulo.

${ }^{1}$ Todas as datas citadas neste texto são a.C., a não ser quando informado o contrário.

2 Trata-se de uma estimativa construída algo arbitrariamente, tendo como base a datação provável do primeiro epinício produzido por Píndaro, a Pítica 10 (498), e o último, a Pítica 8 (446). A informação presente em POxy 2438 (cf. LOBEL, 1961), v.g., faz saber que o poeta foi vitorioso em um concurso de ditirambos em Atenas em 497/6, um ou dois anos depois da composição de sua primeira Pítica.

${ }^{3}$ Race (2012) acentua o impacto do mais importante evento histórico contemporâneo a Píndaro, as Guerras Persas, cujas batalhas de Salamina (480) e Plateia (479) são mencionadas, por exemplo, na Pítica 1.

${ }^{4}$ Gentili (2006, p. xiii) anota que não é improvável pensar que, nos seus inícios, os jogos atléticos congregassem homens oriundos de camadas mais baixas da população. O seu desenvolvimento posterior e sua característica interestatal restringiu os participantes aos estratos mais ricos da população.
} 
no Mediterrâneo. Os grandes complexos sacros de Zeus em Olímpia e em Nemeia, de Apolo em Delfos e de Posêidon na região do Istmo de Corinto sediavam, respectivamente, com periodicidade variável, os grandes jogos Olímpicos, Nemeios, Píticos e Ístmicos, como parte integrante dos festivais dedicados aos seus deuses tutelares $^{5}$. No período helenístico, a divisão do corpus de epinícios de Píndaro em quatro livros foi feita com base na participação do atleta louvado no poema em um dos grandes jogos atléticos pan-helênicos ${ }^{6}$.

O comissionamento de epinícios a poetas como Baquílides e Píndaro, contemporâneos na sua atividade, serviu a diferentes propósitos das famílias aristocráticas que enviavam seus membros para as competições atléticas. O principal deles, não invulgar no horizonte da cultura grega e da função da poesia no milieu em que se encontravam esses poetas, é a perpetuação da fama, ou kleos, no qual poesia funciona como um veículo de memória ${ }^{7}$. Fortemente vinculado às ocasiões de produção e performance ${ }^{8}$, o epinício se constitui como uma amálgama formada por uma série de motivos tradicionais e convenções próprias do gênero (alguns deles intergenéricos, ou seja, presentes na tradição poética grega ou mesmo proto-indo-europeia) ${ }^{9}$ e por elementos que remetem à contemporaneidade de sua representação coral, tanto no que diz respeito às cidades de origem dos vitoriosos louvados quanto ao próprio contexto dos jogos atléticos ${ }^{10}$. Os temas da hubris, a perda do senso de medida justa, da inveja provocada pela vitória e bem-aventurança daquele que é louvado, ao lado da celebração da virtude atlética que se confunde com a noção de aretē heroica fazem parte, entre outros, das reflexões de Píndaro nas passagens gnômicas de seus epinícios. Além disso, as tensões (ideologicamente marcadas) oriundas do retorno do atleta a seu oikos e à comunidade cívica estão, para estudiosos como Kurke (1991), no centro das preocupações também presentes nas celebrações que marcam a performance dos epinícios pindáricos.

No âmbito dos gregos do Ocidente, que ocupavam as cidades fundadas desde o século VIII na Sicília e no sul da Itália, a política de financiamento de poetas está inserida em uma ampla estratégia de legitimação de governantes autocráticos e de seus partidários, na qual a dinastia dos Deinomênidas, sediada em Siracusa, e a dos Emênidas, de Agrigento, souberam especialmente se utilizar da produção poética de seus protegidos, ao lado de projetos construtivos monumentais nas cidades pertencentes

\footnotetext{
${ }^{5}$ Gentili (2006, p. x-xii).

${ }^{6} \mathrm{O}$ grupo de poemas pindáricos reunido pelos editores helenísticos em quatro livros de epinícios não forma, no entanto, um conjunto coeso com características totalmente idênticas. Morgan (2015, p. 2), rememorando as lições de Willcock (1978), explora o fato de que, para além do epinício considerado prototípico, é possível verificar a existência de poemas nos quais algo diverso parece ocorrer. É o caso, por exemplo, da Pítica 3: Currie (2005, p. 344-345) discute a controvérsia em torno da datação do poema, a inexistência de uma vitória atlética nos Jogos Píticos ligada diretamente à composição, bem como sua matéria, eminentemente consolatória, visto que Hierão se encontra adoentado, ao lado de uma série de referências sobre a imortalização através do canto e da heroicização do tirano. Cf. Young (1983) para uma análise detida dos problemas interpretativos em torno das Píticas 2 e 3, ambas dedicadas a Hierão.

${ }^{7} \mathrm{O}$ trabalho de Currie (2005) explora o tema do culto heroico na religião grega do século $\mathrm{V}$ ao lado de uma análise aprofundada dos epinícios de Píndaro que usam de imagens e topoi relacionados à heroicização, tal como as diferentes noções a respeito da imortalidade, em especial àquela proporcionada pela poesia.

${ }^{8}$ O trabalho de Krummen (2014) - originalmente publicado em língua alemã em 1990 - trouxe novo ímpeto às discussões sobre a ocasionalidade dos epinícios pindáricos.

${ }^{9}$ Watkins (1995, pp. 448-459) explora, dentre outros temas, as raízes proto-indo-europeias do mito de Tifeu e de como Píndaro o recepciona. Cf. também Nagy (1990) e Maslov (2015).

${ }^{10}$ Race (2012, p. 16).
} 
a seus domínios e nos santuários pan-helênicos nos Bálcãs ${ }^{11}$. Em que pesem algumas importantes diferenças tanto o público local quanto o mais amplo, na Grécia balcânica, estava inserido nesse complexo jogo de representações que envolviam a legitimação dos poderes estabelecidos, tal como o pertencimento a uma ideia geral de helenidade na qual os tiranos e as populações do amplo domínio colonial grego buscavam se ver incluídos.

A primeira das Píticas cumpre a função de celebrar tanto a vitória do tirano na quadriga nas competições délficas como a fundação, cerca de cinco anos antes, de uma nova cidade, Etna, remodelada a partir de Catânia, antiga fundação jônica, por meio do sinecismo de habitantes de Siracusa e de um grupo de colonos do Peloponeso (Diod. Sic. $11,49.1)^{12}$. O ato singular de fundar uma nova cidade mimetiza o papel envolto em sacralidade dos oikistai, fundadores das primeiras colônias (apoikiai) no Mediterrâneo ocidental, e serve de mote para o elogio do reinado sem igual de Hierão na Sicília. A vitória atlética, como pontua Morgan ${ }^{13}$, constitui-se como um bom presságio a respeito do futuro da nova cidade.

Representada primeiro, como conjectura Morrison ${ }^{14}$, diante de um público siciliota, a Pítica $1^{15}$ fomenta a discussão da permeabilidade do epinício a outras funções além do prototípico elogio da vitória atlética e de suas repercussões no seio da comunidade que forma a pólis quando do retorno do vencedor. O que está em questão é a existência de uma "poética da colonização", na feliz expressão de Dougherty (1993), que foi sedimentada por meio de diversas espécies da poesia mélica ou lírica nos períodos Arcaico e Clássico.

Dougherty (1994, p. 35) argumenta que, a despeito de narrativas sobre a fundação de cidades aparecerem na literatura grega arcaica, a poesia de ktisis ("fundação") não assumiu a forma de um gênero literário autônomo, como comumente se acreditava. O pertencimento de uma composição a determinado gênero literário era pautado, na poesia grega arcaica, pela ocasião de performance e não pelo seu conteúdo. Não havendo evidências de ocasiões específicas para as quais a poesia de ktisis teria sido intencionalmente composta, a autora defende que as narrativas de fundação estariam inseridas em outros gêneros, como parte de um projeto poético maior. Seria mais adequado dizer que a ktisis atua como um topos literário que adiciona informações de caráter geográfico e etiológico em uma variedade de contextos poéticos e ocasionais.

Figura avaliada ambiguamente nas fontes escritas ${ }^{16}$, Hierão de Siracusa é retratado por Píndaro na Pítica 1 como correspondente a Zeus no plano humano.

\footnotetext{
${ }^{11}$ Hirata (2009) explora em especial as estratégias de representação do poder em Siracusa sob os governos de Gelão e Hierão e em Agrigento sob o governo de Terão com foco especial na monumentalização de edifícios públicos, principalmente aqueles construídos subsequentemente à Batalha de Himera (480). O comissionamento de odes a Píndaro e Baquílides pelos tiranos Hierão e Terão é, para a arqueóloga, parte deste contexto de legitimação das tiranias siciliotas. Também fez parte da afirmação do poder dos siciliotas em um contexto pan-helênico a representação de tragédias áticas na Sicília; cf. Kowalzig (2008).

${ }^{12}$ Gentili (2006, p. 19) defende que o encômio a Hierão transcende sua vitória atlética na prestigiosa modalidade da quadriga para focar-se primariamente na celebração da fundação de Etna.

${ }^{13}$ Morgan (2015, p. 320-326).

${ }_{15}^{14}$ Morrison (2007, pp. 65-66).

${ }^{15}$ Sobre a ocasião primeira de performance, Gentili (2006, p. 9) e Morgan (2015, p. 346-347) exploram as relações entre a Pítica 1 e o Epinício 4 de Baquílides, ambos comissionados para celebrar a vitória do tirano Deinomênida na corrida de quadriga nos Jogos Píticos. No poema de Baquílides, diferentemente do que se verifica no epinício pindárico, Hierão é cognominado "de Siracusa". A brevidade do epinício de Baquílides permite supor que ele havia sido comissionado para ser representado no local da vitória, ao passo que a Pítica 1 seria destinada a celebrações cívicas na cidade de Etna.

${ }_{16}$ Diodoro Sículo, por exemplo, em 11, 67, trata da sucessão de Hierão e informa que seu irmão Trasibulo, que assumiu o trono após sua morte, superava-o em maldade.
} 
Enquanto que o rei dos deuses instaurou a ordem na sua disputa final com Tifeu, o rei de Etna e dos siracusanos pacificou a Sicília e dissolveu a ameaça bárbara. Jazendo, como diz Píndaro, pressionado pelo monte homônimo junto à colônia fundada por Hierão, Tifeu é um portento de se ver e evoca a memória do poder de Zeus.

A utilização de um vocabulário qualificativo que evoca os basileis da tradição hexamétrica $^{17}$, cujo poder deriva da concessão do cetro por Zeus, e a determinação do tirano retratado por Píndaro em fundar uma pólis dotada de uma constituição política de tipo dórica ${ }^{18}$ deixam entrever a busca pela representação de um soberano que, ao mesmo tempo em que produz efeitos entre os seus próprios súditos, encontre, através de outras performances do poema, legitimidade entre um público pan-helênico cada vez menos tolerante às tiranias e mobilize a reafirmação de laços de etnicidade com as populações da Grécia balcânica. O estabelecimento de sincronismos entre os conflitos que opuseram gregos e persas na Grécia balcânica e gregos e cartagineses na Sicília $(P .1$, 72-75) ${ }^{19}$, cujas versões alternativas encontramos em Heródoto (7, 158-162), também contribuem para o delineamento do projeto político levado a cabo pelos Deinomênidas ${ }^{20}$.

A própria ausência de um vocabulário diretamente ligado à tirania na Pítica $1^{21}$ permite entrever uma preocupação especial no que diz respeito à recepção do poema. A pesquisa arqueológica ${ }^{22}$, que possibilitou a descoberta da documentação material relacionada ao período dos tiranos Deinomênidas, produziu importantes resultados que merecem ser levados em consideração em estudos que busquem compreender melhor os elementos do contexto de performance dos epinícios de Píndaro. Monumentos e artefatos dedicados em Delfos e Olímpia pela dinastia, ao lado de informações colhidas da documentação epigráfica ${ }^{23}$, permitem-nos avaliar conjuntamente as estratégias de

\footnotetext{
${ }^{17}$ Harrell (2002, pp. 440-450).

${ }^{18}$ P. 1, 60-68. Morgan (2015, p. 334-335) explora as intenções do "constitucionalismo dórico" mencionado por Píndaro como adotado por Hierão. É possível conjecturar que a natureza diárquica e estável da constituição política dos espartanos pudesse ser transposta em uma monarquia dividida de acordo com as quatro tribos dóricas em Etna como pretendeu Hierão. Trata-se de laços simbólicos que contribuem para a legitimação do governo tirânico e de certa atenuação de sua imagem.

${ }^{19}$ A menção, por Píndaro, da vitória das forças de Hierão sobre os etruscos em Cumas (474) nessa mesma passagem visa incluir a vitória do tirano no movimento de combate dos gregos aos bárbaros a leste e a oeste.

${ }^{20}$ Harrell (2006) explora a tensão existente entre o local e o pan-helênico nas narrativas de sincronia entre as batalhas de Himera, no contexto das guerras entre os exércitos capitaneados pelos Deinomênidas contra os Cartagineses, e de Salamina e Plateia, importantes vitórias gregas durante as Guerras Persas.

${ }^{21} \mathrm{O}$ único uso de turannos nas odes comissionadas a Píndaro por Hierão aparece em $P$. 3,70, em uma passagem gnômica; antes, porém, Hierão é qualificado como basileus por três vezes (HARRELL, 2002, p. 440). Cf. Morgan (2003) para uma investigação abrangente a respeito das diferentes abordagens possíveis sobre a tirania entre os gregos. Raaflaub (2003, p. 60) explica que o termo "tirania" foi utilizado na Antiguidade e continua a sê-lo modernamente para abarcar diferentes tipos de governos autocráticos. Uma separação estrita entre os sentidos de basileia e turannis, o primeiro termo indicando um governo monárquico legítimo e o segundo, um governo ilegítimo, apenas emerge tardiamente, sobretudo a partir de Tucídides. Percebe-se, pois, que "tirania" permaneceu com um sentido ambivalente até sua definitiva caracterização como uma forma de governo negativa. Se observarmos a passagem dedicada à ascensão de Pisístrato ao poder em Atenas na Constituição dos Atenienses (14.3), atribuída a Aristóteles (2003, p. 41), é significativo notar que, ainda no século IV, a atuação do mais célebre dos tiranos de Atenas é avaliada de forma relativamente positiva, pois lá é dito que "depois de tomar o poder, conduziu os interesses comuns mais à maneira de um cidadão que de um tirano".

${ }^{22}$ Hirata (1996/1997 e 2009) tem produzido estudos a respeito do papel dos epinícios nas estratégias de consolidação e exteriorização do poder pelas tiranias siciliotas do século V.

${ }^{23}$ Há um conjunto de três trípodes com base de campânula no terraço cerimonial do templo de Apolo em Delfos ligados aos Deinomênidas (MEIGSS e LEWIS, 1969): uma das bases contém uma inscrição epigráfica (ML 28) atribuindo a dedicação a Gelão. Três elmos encontrados em Olímpia contêm uma
} 
representação do poder pelos tiranos siciliotas. A aparente contradição, como anota Harrell (2002), entre o cidadão que, enquanto pessoa privada originária de Siracusa, faz sua oferta em nome de si e de seus compatriotas nos santuários do continente e a figura de um soberano legítimo e que governa sozinho como é o Hierão que se pode encontrar em Píndaro, denota a permanente situação de ambiguidade em que se encontravam os tiranos da Sicília e reforça a tese de que a ausência de uma nomenclatura própria da tirania é significativa para a interpretação da Pítica 1 .

\section{Sobre a tradução}

Esta tradução baseia-se, majoritariamente, na edição das Píticas elaborada por Snell e Mahler (1980). Em certas passagens, sempre apontadas e justificadas por meio de notas, optou-se pela tradução do texto estabelecido por Gentili (2006).

$\mathrm{O}$ recurso às notas visa esclarecer passagens de interpretação problemática no texto grego e fornecer informações a respeito de regiões geográficas, bem como de personagens históricas e mitológicas citadas no poema.

O trabalho tradutório visou, sempre que possível, produzir um texto mais acessível ao leitor em português, sacrificando, assim, a natureza sintética de muitas construções utilizadas por Píndaro, substituindo-as por versões mais estendidas. O mesmo se aplica à sintaxe pindárica, muitas vezes adaptada de forma a se privilegiar o sentido.

\section{Tradução}

Pítica 1: Para Hierão de Etna, vencedor na quadriga (470)

Lira de ouro, posse legítima de Apolo e das Musas

estr. 1

de mechas violáceas: a ela o passo de dança

escuta, princípio da festividade,

e os cantores obedecem às tuas notas,

quando, vibrando, compões os acordes iniciais

dos prelúdios que guiam os coros.

Também extingues o raio afiado

de fogo perene. E sobre o cetro

de Zeus a águia dorme,

tendo pousado a asa veloz nos dois lados,

a soberana das aves. Sobre sua recurva cabeça

ant. 1

verteste nuvem de negra face,

inscrição com uma dedicação de Hierão e dos siracusanos (ML 29); cf. (HARRELL, 2002). Morgan (2015, pp. 66-67) explora a iconografia de um tetradracma emitido por Etna, cujos detalhes encontram paralelos com séries de moedas emitidas por Siracusa durante o governo dos Deinomênidas. O reverso da moeda apresenta a figura de Zeus sentado em um trono, segurando em uma mão um raio e em outra um cetro, no qual uma águia está pousada. Há conjecturas de que se trate de Zeus Aitnaios, divindade tutelar da fundação, e que sua representação seja evocada na narrativa a respeito do poder do canto no primeiro par de estrofes e antístrofe da Pítica 1. Laky (2016) realizou um importante estudo arqueológico a respeito do papel político do culto de Zeus nas pólis helênicas e na construção de redes de identidades no contexto dos territórios ocupados por populações de origem grega no Mediterrâneo, organizadas sob a forma de pólis. O trabalho se vale de um amplo conjunto de documentação material, formado por santuários, datados a partir da Idade do Bronze aos fins do período Clássico (344/5) e de moedas cunhadas desde o período Arcaico até o fim do período Clássico. Nele a arqueóloga explora a iconografia da moeda de Etna que nos interessa para o estudo da Pítica 1, inserida em um contexto mais amplo de emissões monetárias feitas por diferentes pólis, nas quais a figura de Zeus entronizado com uma águia pousada em seu cetro é retratada. 
fechadura prazerosa das pálpebras:

dormindo, ela eriça o dorso fluido,

dominada pelo estremecimento das tuas notas.

Sim, o violento Ares, após deixar longe a áspera

10

ponta das lanças, aquece seu coração com o repouso,

e tuas flechas encantam até a mente dos deuses

devido à perícia do filho de Leto ${ }^{24}$

e das Musas bem-drapeadas.

Mas os muitos que Zeus não ama paralisam-se de terror

ep. 1

quando ouvem o grito das Piérides ${ }^{25}$

sobre a terra e o mar indômito,

entre eles, jazendo no horrífico Tártaro, inimigo dos deuses,

Tifeu ${ }^{26}$ de cem cabeças, a quem outrora

a famosa caverna da Cilícia ${ }^{27}$ nutriu; agora

as escarpas que cercam o mar sobre Cumas ${ }^{28}$

e a Sicília pressionam

seu peito hirsuto. Coluna celeste o oprime,

o Etna nevado, o ano todo, nutriz de gelo cortante,

cujas fontes consagradas vomitam das profundezas

estr. 2

fogo inaproximável; durante os dias os rios

despejam fluxo de fumaça ardente.

Mas na escuridão da noite

rubra chama rolando carrega rochas

para o profundo assoalho do mar com estrépito.

Aquele monstro faz jorrar as mais terríveis

torrentes de Hefesto. Portento

maravilhoso de se mirar,

e maravilha até de se ouvir de quem o presenciou -

esse está preso entre os picos de folhas negras do Etna

ant. 2

e a planície, e o leito lhe dilacera e pica todo

o dorso reclinado.

Conceda, Zeus, conceda agradar-te,

tu que governas sobre esta montanha,

fronte de terra fértil, a quem a epônima

cidade vizinha o renomado fundador

glorificou: na pista pítica

mencionou-a o arauto,

proclamando Hierão bela-vitória

\footnotetext{
${ }^{24}$ Apolo, filho de Zeus e Leto. Cf. Hino Homérico a Apolo (CABRAL, 2004).

${ }^{25}$ As Musas; de acordo com Hesíodo (Teogonia, vv. 53-55), as deusas nasceram da união entre Zeus e Memória (Mnēmosunē).

${ }^{26}$ Tifeu ou Tífon, último oponente de Zeus (cf. HESÍODO, Teogonia, v. 820-880).

${ }^{27}$ Nome antigo de região localizada na Ásia Menor (atual Turquia).

${ }^{28}$ Fundação grega no sul da península itálica datada do século VIII. Foi palco da batalha naval entre as forças de Hierão e os etruscos em 474.
} 
por ocasião da quadriga. Aos nautas a primeira graça

ep. 2

para navegar é a vinda de brisa favorável

no início, pois é provável

também no fim obter melhor retorno. Esse preceito

em tais sucessos traz a expectativa

que no futuro Etna será famosa pelas coroas e cavalos

e seu nome celebrado em sonoros festejos.

Lício e $\mathrm{Febo}^{29}$, que governa sobre Delos

e ama a fonte Castália do Parnasso,

queiras por isso em tua mente e dar bravos homens a essa terra.

Dos deuses provém todo meio para os sucessos dos mortais,

estr. 3

e eles nascem sábios, fortes nas mãos

e eloquentes. Aquele homem

desejando louvar com ardor, espero, por assim dizer,

não lançar para fora do estádio a lança brônzea

que estou brandindo na mão,

mas lançá-la longe e superar os adversários.

Possa todo o porvir assim conduzi-lo

à felicidade e à dádiva dos bens

e fornecer o esquecimento das fadigas.

Por certo ele recordaria em quais batalhas nas guerras

ant. 3

com espírito firme perseverou, quando

pelas mãos dos deuses encontraram ${ }^{30}$ honraria

tal que nenhum dos helenos colhe,

coroa altiva de riqueza. Mesmo agora,

à maneira de Filoctetes ${ }^{31}$,

foi para a guerra. Por necessidade, alguém,

embora sendo orgulhoso, bajulou-o como amigo.

Dizem que vieram heróis ${ }^{32}$

divinos para levar de Lemnos

o arqueiro filho de Peante, angustiado pela ferida:

ele destruiu a pólis de Príamo e findou os trabalhos dos dânaos, caminhando com o corpo fraco, mas era o destino.

ep. 3

Que assim o deus seja protetor de Hierão,

\footnotetext{
${ }^{29}$ Phoibos, Febo e Lukios, Lício, são epítetos de Apolo.

${ }^{30}$ A saber, Hierão e seus irmãos.

${ }^{31}$ Herói do ciclo troiano da tradição hexamétrica, personagem central da tragédia homônima de Sófocles. É citado por Homero no "catálogo das naus" da Ilíada (II, vv. 716-724): vindo da Taumácia, comandava sete navios. Arqueiro exímio, foi abandonado na ilha de Lemnos (no Egeu setentrional) devido ao odor fétido que exalava de sua ferida, resultado da mordida de uma serpente. É mencionado duas vezes na Odisseia (III, v. 190 e VIII, v. 219), na primeira passagem como tendo sido um dos heróis que retornaram da guerra e na segunda como o melhor dos arqueiros de Troia (cf. MURRAY, 1919 e 1924). No argumento da Pequena Ilíada extraído da Crestomatia de Proclo (cf. WEST, 2003, p. 121) consta que Diomedes, juntamente com Odisseu, trouxe o herói para Troia em virtude de uma profecia segundo a qual a cidade teucra somente poderia ser tomada com o arco de Héracles, propriedade de Filoctetes.

${ }^{32} \mathrm{Na}$ tradução desta passagem (vv. 52-54), a fim de produzir uma construção mais fluida em português, optou-se por rearranjar a distribuição das palavras entre a antístrofe e o epodo em relação ao original grego.
} 
no tempo que se aproxima, dando a medida justa

do que deseja.

Atenda-me, Musa, e também junto de Deinomenes ${ }^{33}$ celebra

o prêmio da quadriga:

não é alegria alheia a vitória de um pai.

Vamos, encontremos para o rei de Etna um hino amistoso.

Para ele Hierão fundou essa cidade com liberdade divina

estr. 4

nas leis do governo de $\mathrm{Hilo}^{34}$ :

querem os descendentes de Pânfilo ${ }^{35}$

e por certo os dos Heráclidas,

que vivem sob as encostas do Taigeto, sempre

permanecer nos preceitos de Egímio,

como dóricos. Afortunados, ocuparam Amiclas ${ }^{36}$

vindos do Pindo ${ }^{37}$

vizinhos ilustres ${ }^{38}$ dos Tindáridas ${ }^{39}$ de alvos corcéis,

e a fama de suas lanças floresceu.

Ó Zeus Realizador, determina que sempre tal

seja a sorte para os cidadãos e reis junto da água do Amenas: ${ }^{40}$

ant. 4

um discurso veraz dos homens.

Contigo o homem que lidera,

dando ordens ao filho, honraria o povo

e o guiaria para harmoniosa concórdia ${ }^{41}$.

Suplico, ó Cronida: concede que quieto

permaneça em casa o grito de guerra

do fenício e dos tirrenos ${ }^{42}$, que viram

sua violência lamentar os navios diante de Cumas,

o que sofreram conquistados pelo líder dos siracusanos,

ep. 4

o qual lançou das naus velozes a juventude deles no mar,

livrando a Hélade da pesada escravidão. Obterei

de Salamina ${ }^{43}$ a gratidão dos atenienses como recompensa

e em Esparta falarei da batalha defronte ao Citero ${ }^{44}$,

\footnotetext{
${ }^{33}$ Filho de Hierão de Siracusa, rei recém-empossado de Etna.

${ }^{34}$ Primeiro filho de Héracles e Dejanira.

${ }^{35}$ Filho de Egímio, que era filho de Doro: morreu combatendo Tisameno com os Heráclidas.

${ }^{36}$ Uma das vilas de Esparta.

${ }^{37}$ Cadeia montanhosa na Tessália.

${ }^{38}$ Literalmene "vizinhos de reputação profunda dos Tindáridas", Tundaridan bathudoxoi geítones.

${ }^{39}$ Dióscuros, os irmãos gêmeos de Helena.

${ }^{40}$ Rio de Etna.

${ }^{41} \mathrm{O}$ vocábulo hēsukhia foi traduzido nesta passagem por "concórdia". A opção teve a finalidade de explicitar o valor político do termo, o que não ocorreria caso se optasse por "calma" ou "tranquilidade". Gentili (2006, p. 353-354) salienta que o termo diz respeito à paz interna na cidade, "à concórdia entre os astoi e os basileis" (tradução nossa), não podendo ser excluída, no entanto, à luz dos versos seguintes, a alusão pindárica à manutenção da paz externa.

42 Etruscos.

${ }^{43}$ Referência à batalha que transcorreu entre gregos e persas no estreito que separa a ilha de Salamina da Ática em 480.

${ }^{44}$ Monte na Beócia, defronte ao qual se desenrolou a batalha de Plateia (479). Este verso (77) foi traduzido de acordo com o texto fixado na edição de Gentili (2006): diferentemente do que consta na
} 
nas quais penaram os Medas ${ }^{45}$ de arcos recurvos,

e, junto da margem abundante em água

do Himera ${ }^{46}$, finalizarei um hino para os filhos de Deinomenes, ${ }^{47}$

que eles receberam devido à sua excelência,

tendo os homens inimigos penado.

Se falares de modo oportuno, atando os fios de muitos temas

est. 5

com brevidade, menor é a censura que provém

dos homens, pois o perpétuo excesso enfraquece ${ }^{48}$

as esperanças velozes,

e sobretudo o relato do sucesso dos outros

pesa no secreto coração dos cidadãos.

No entanto, como a inveja é melhor que a compaixão,

não desconsideres as ações nobres.

Guia, com justo leme, o povo

e forja a língua numa bigorna sem mentiras.

Mesmo se algo banal faísca ${ }^{49}$, torna-se grande quando vem

ant. 5

de ti. És guardião de muitas coisas.

Muitas são as testemunhas fiéis de ambos.

Mantendo-se com florescente índole,

se de fato estimas sempre ouvir relato

doce, não te aborreças em demasia com as despesas;

desfralda como o timoneiro

que estende a vela ao vento. Não sejas enganado,

ó amigo, pelos ganhos cambiáveis,

pois somente o orgulho póstumo da fama,

só ele, revela a vida dos homens que partiram

ep. 5

aos cronistas e poetas.

Não perece a benigna excelência de Creso ${ }^{50}$.

Odioso rumor em toda parte domina Fálaris ${ }^{51}$, de mente

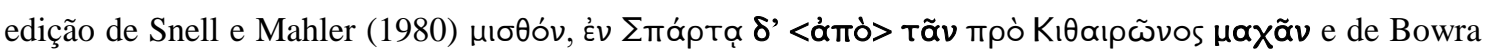

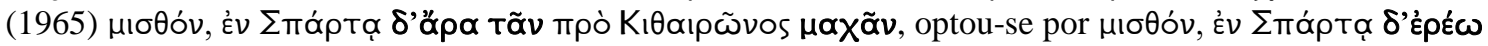

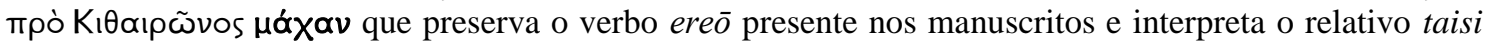

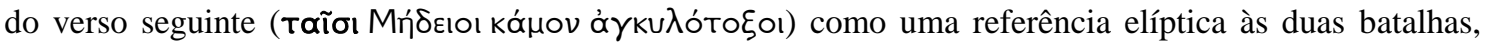
Salamina e Plateia.

${ }^{45}$ Persas.

${ }^{46}$ Rio da Sicília.

${ }^{47}$ Pai de Hierão e Gelão de Siracusa.

${ }^{48}$ Literalmente "embotar", "fazer perder o corte" (amblunō).

${ }^{49}$ Nesta passagem, optou-se por adotar a interpretação de Gentili (2006, p. 359) na tradução do raro verbo paraithussō por "faiscar". Para Gentili, "paraithussei continua a metáfora da bigorna, aludindo as faíscas que saem da língua de Hierão" (tradução nossa)".

${ }^{50}$ Rei da Lídia, mencionado no Epinício 3 de Baquílides (cf. MAHLER, 2003), dedicado a Hierão de Siracusa. No poema de Baquílides (vv. 23-61), o monarca é salvo da pira sacrificial que preparou para si e para a família graças às intervenções de Zeus e Apolo: o primeiro por apagar as chamas, fazendo chover, e o segundo por resgatar Creso e levá-lo ao país dos Hiperbóreos. Heródoto (2008), no primeiro livro das Histórias, narra a mudança de sorte pela qual passou Creso quando seu reino foi invadido por Ciro da Pérsia (546/7). Segundo o historiógrafo de Halicarnasso (Histórias, I, 86), Ciro reconheceu sua beatitude quando estava prestes a atirá-lo a uma pira, ao ficar intrigado com as repetidas menções de Creso a Sólon. ${ }^{51}$ Contra-exemplo à beatitude de Creso, Fálaris foi tirano de Acragas (Agrigento) em torno de 571-555. Várias fontes, dentre elas Diodoro Sículo (IX, 18-19), relatam sua proverbial crueldade: mandou fazer um 
impiedosa, que queimava em touro de bronze as vítimas,

e nem o acolhem as liras sob os tetos

em amena companhia com vozes de meninos.

O sucesso é o primeiro prêmio,

e o renome é o segundo quinhão; o homem que a ambos

encontra e toma, recebeu a suma coroa.

100

\section{Agradecimentos}

Agradecemos à Fundação de Amparo à Pesquisa do Estado de São Paulo (FAPESP), pelo financiamento concedido; e aos revisores da Rónai pela valiosa contribuição ao trabalho, oriunda de sua avaliação minuciosa.

\section{REFERÊNCIAS}

ARISTÓTELES. Constituição dos Atenienses. Tradução e notas de Delfim F. Leão. Lisboa: Fundação Calouste Gulbenkian, 2003.

BOWRA, C. M. (Ed.). Pindari carmina: cum fragmentis. $2^{\mathrm{a}}$ ed. Oxford: Clarendon Press, 1965. (Scriptorum Classicorum Bibliotheca Oxoniensis).

CABRAL, L.A.M. Hino Homérico a Apolo: Introdução, tradução, comentários e notas. Cotia: Ateliê Editorial, 2004.

CURRIE, B. Pindar and the cult of heroes. Oxford: Oxford University Press, 2005.

DIODORO SÍCULO. The Library of History. Tradução de C.H. Oldfather. Cambridge, MA/Londres, 1989. v. 4. (The Loeb Classical Library).

DOUGHERTY, C. The poetics of colonization: from city to text in archaic Greece. Oxford: Oxford University Press, 1993.

Archaic Greek Foundation Poetry: Questions of Genre and Occasion. The Journal of Hellenic Studies, Cambridge: Society for the Promotion of Hellenic Studies/Cambridge University Press, v. 114, pp. 35-46, 1994.

GENTILI, B. (Ed.). Pindaro: Le Pitiche. Colaboração de Ettore Cingano, Paola Angeli Bernardini e Pietro Giannini. $4^{\mathrm{a}}$ ed. Roma: Fondazione Lorenzo Valla/Arnaldo Mondadori Editore, 2006. (Pindaro: Le Odi, 2).

HARRELL, S. King or private citizen: fifth-century sicilian tyrants at Olympia and Delphi. Mnemosyne, Leiden: Brill, v. 55, n. 4, pp. 439-464, 2002.

Synchronicity: The Local and the Panhellenic Within Sicilian Tyranny. In: LEWIS, S. (Ed.). Ancient tyranny. Edimburgo: Edinburgh University Press: 2006.

HERÓDOTO. The Histories. Tradução de Robin Waterfield, introdução e notas Carolyn Dewald. Oxford: Oxford University Press, 2008.

HESÍODO. Teogonia. Organização e tradução de Christian Werner. São Paulo: Hedra, 2013.

touro de bronze, dentro do qual aprisionava suas vítimas e as queimava. Da boca do animal brônzeo saíam seus lamentos, semelhantes a mugidos (GENTILI, 2006, p. 362). 
HIRATA, E. F. V. As odes de Píndaro e as tiranias siciliotas. Classica. São Paulo: Sociedade Brasilera de Estudos Clássicos, v.9/10, n. 9/10, pp. 61-72, 1996/1997.

Monumentalidade e representações do poder de uma pólis colonial. In: FLORENZANO, M. B. B.; HIRATA, E.F.V. (Org.). Estudos sobre a cidade antiga. São Paulo: Edusp/Fapesp, 2009. pp. 121-136.

KOWALZIG, B. Nothing to do with Demeter? Something to do with Sicily! Theatre and society in the early fifth-century west. In: REVERMANN, M.; WILSON, P. (Org.). Performance, iconography, reception: studies in honour of Oliver Taplin. Oxford: Oxford University Press, 2008. pp. 128-60.

KURKE, L. The traffic in praise: Pindar and the poetics of social economy. Ithaca: Cornell University Press, 1991. (Myth and Poetics).

KRUMMEN, E. Cult, myth, and occasion in Pindar's victory odes: a study of Isthmian 4, Pythian 5, Olympian 1, and Olympian 3. Tradução de J.G. Howie: Prenton: Francis Cairns, 2014.

LAKY, L. A. A apropriação e consolidação do culto de Zeus pela cidade grega: moedas e santuários, política e identidade em época arcaica e clássica. 2016. Tese (Doutorado em Arqueologia) - Museu de Arqueologia e Etnologia, Universidade de São Paulo, São Paulo, 2016.

LOBEL, E. (Ed.). The Oxyrhynchus Papyri: Part 26. Londres: Egypt Exploration Society, 1961 (Graeco-Roman Memoirs).

MAHLER, H. (Ed.). Bacchylides: Carmina cum fragmentis. 11ª ed. Munique e Leipzig: De Gruyter, 2003. (Bibliotheca Scriptorum Graecorum et Romanorum Teubneriana).

MASLOV, B. Pindar and the emergence of literature. Cambridge: Cambridge University Press, 2015.

MEIGGS, R.; LEWIS, D. M. Selection of Greek historical inscriptions to the end of the fifth century BC. Oxford: Clarendon Press, 1969.

MORGAN, K. A. (Ed.). Popular tyranny. Austin: University of Texas Press, 2003. (Sovereignty and itd discontents in Ancient Greece).

Pindar and the construction of Syracusan monarchy in the fifth century B.C. Oxford: Oxford University Press, 2015. (Greeks Overseas).

MORRISON, A. D. Performances and audiences in Pindar's Sicilian victory odes. Londres: Institute of Classical Studies, 2007.

MURRAY, J.T. (Ed.). Homer: Odyssey. Cambridge/Londres: Harvard University Press, 1919. (The Loeb Classical Library).

. Homer: Iliad. Cambridge/Londres: Harvard University Press, 1924. (The Loeb Classical Library).

NAGY, G. Pindar's Homer: the lyric possession of an epic past. Baltimore/Londres: Johns Hopkins University Press, 1990. 
RAAFLAUB, K. Stick and glue: the function of tyranny in fifth-century Athenian democracy In: MORGAN, K.A. (Ed.). Popular tyranny. Austin: University of Texas Press, 2003. (Sovereignty and itd discontents in Ancient Greece).

RACE, W. H. (Ed.). Pindar I: Olympian odes; Pythian odes. 2a ed. Cambridge, MA/Londres: 2012. v. 1. (The Loeb Classical Library).

SNELL, B.; MAHLER, H. (Ed) Pindari carmina cum fragmentis. Leipzig: BSB B.G. Teubner Verlagsgesellschaft, 1980. 2 v. (Bibliotheca Scriptorum Graecorum et Romanorum Teubneriana).

YOUNG, D.C. Pythians 2 and 3: Inscriptional $\pi$ o $\tau \varepsilon$ and the "Poetic Epistle". Harvard Studies in Classical Philology. Cambridge: Department of the Classics, Harvard University, v. 87, pp. 31-48, 1983.

WATKINS, C. How to kill a dragon: aspects of Indo-european poetics. New York: Oxford University Press, 1995.

WILLCOCK, M. M. On first reading Pindar: the fifth Isthmian. Greece \& Rome. Cambridge: The Classical Association/Cambridge University Press, v. 25, n. 1, pp. 3745, 1978.

Data de envio: 20-04-2018

Data de aprovação: 05-06-2018

Data de publicação: $15-08-2018$ 